\title{
iWDSS-Tender: Intelligent Web-based Decision Support System for Tender Evaluation
}

\author{
Noor Maizura Mohamad Noor and Mustafa Man \\ Universiti Malaysia Terengganu \\ Malaysia
}

\section{Introduction}

Tender evaluation for tendering process is crucial and critical because the tender selection is not only benefits both client and contractor, but also affecting their reputations in the future. In current practice, tender evaluation is performed by human or decision makers (DMs). We are using tender process standard from Jabatan Kerja Raya Malaysia (JKRM) as guidance since this standard is widely used by organizations in the country.

However, there are few constraints of the DMs and the current practice that can affect the accuracy and transparency of the decisions. Tender process usually takes a long time to finish since it involves a lot of steps and procedures. DMs might make mistakes or misjudge alternatives in making decisions. Besides, some other issues such as corruption and resource misuses can possibly happen. As a solution, the development of a computerized system to assist the tender evaluation process is a brilliant idea.

This paper introduces Intelligent Web-based Decision Support System (DSS) as a perfect solution for tender evaluation process. DSSs are computer program that aids DMs in problem solving or decision-making environment. An important performance objective of DSS is to support all phases of the decision-making process (Sprague R. H. Jr., 1982). DSS should not replace the functions of the DMs but gives a recommendation based on input by DMs.

DSS also can be described as computer-based interactive human-computer decision-making system that (Eom, 2001) support decision makers rather than replaces them, utilizes data and models, solves problems with ranging degree of structure (unstructured or illstructured, semi-structured, semi-structured and unstructured) and focuses on effectiveness rather than efficiency in decision processes (facilitating decision process).

Intelligent DSS (iDSS) or also referred as Knowledge based DSS (KBDSS) is a comprehensive computer program which solves problems within a limited and specific field, using data on the problem, knowledge related to the problem, and intelligent decision-making capabilities (Fakhreddine O. Karray, 2004). iDSS is a DSS that integrates knowledge from experts. It is actually enhance the capabilities of decision support by supplying tool that directly support DMs and enhancing various computerized DSS (Turban et al., 2005).

World Wide Web (WWW) which offers universal information availability and userfriendliness become the best platform for the delivery of iDSS. This Intelligent Web-based DSS for Tender Evaluation (iWDSS-Tender) enables users to access the system from different locations and perform decision-making in just a few clicks. 
The intelligence element is added in the DSS because intelligent systems have the capabilities of perception, reasoning, learning and making decisions from incomplete information (Fakhreddine O. Karray, 2004). DSS is expected to assist DMs to select among available alternatives, while intelligent is seen as an element that helps the system to make more accurate decisions. The study aims to achieve the following objectives:

i. To design and develop a framework for an iDSS,

ii. To develop an efficient Web-based iDSS for tender evaluation system,

iii. To test and analyze by demonstrating the applicability of the approach using a real world scenario.

This paper is divided into eight sections. Section 1 discussed the Introduction. Section 2 briefs the current electronic tendering process systems. Section 3 states the purposes of the research. Section 4 explains the approach of the research. Two major phases in tender evaluation process are explained in Section 5. Section 6 describes the research framework of the research. Then followed by the expected result in Section 7 and conclusions in Section 8 .

\section{Related work}

\section{a) Current electronic tendering applications}

There are a few electronic applications in the market now such as e-Perolehan, TenderDirect and TenderSystem. e-Perolehan is an electronic procurement application system developed by Malaysian Government to help procurement activities and to increase the quality of services provided by the government. e-Perolehan has a tender module that enables suppliers or contractors to send quotations, download tender document and upload tender offer. TenderDirect is a system which is using a one-stop centre approach. This system will collect and gather all tenders information in Tender Collection Centre. TenderDirect involves downloading, payment and printing of tender documents. It serves contractors as a notice board system that will send alert messages via email, fax, telephone or pager. These alert messages contain latest tenders' updates and they need to check the website for further details.

TenderSystem also provides suppliers or contractors with downloading, uploading, quoting and alert system. Some of the systems allow contractors to buy the tender documents. But all current electronic procurement or Web-based tendering systems only provide the same process such as download, upload, quote and alert system, and also serve as a notice board to display tenders' information. To overcome the limitations of current electronic tendering applications, we propose to employ artificial intelligence technique as an improved element for the system.

\section{b) Artificial intelligence}

The term Artificial Intelligence (AI) was first used by John McCarthy who used it to mean "the science and engineering of making intelligent machines" (McCarthy, 2004). Artificial Neural Network (Haykin, 1994) is a massive parallel distributed processor that has a natural propensity for storing experiential knowledge and making it available for use. It resembles the brain in two respects. The first is knowledge acquired by the network through a learning process and the second is inter-neuron connection strengths known as synaptic weights are used to store the knowledge. Tender evaluation requires few criteria to be considered before any decision is made; therefore we propose multicriteria decision analysis methods. 


\section{c) Multicriteria Decision analysis Methods (MCDM)}

In tender evaluation phase for tendering process, few criteria such as financial background, experiences, reputation and so on are taking into account. We need to rank the criteria based on their priority before we calculate points for each tender. Since it involves ranking different and conflicting criteria, we conclude that it is a multicriteria decision-making problem. Multicriteria Decision Analysis Methods are proposed to overcome the problem of multicriteria decision-making. There are three broad categories of Multicriteria Decision Analysis Methods:

a. Value measurement models is s numerical score (or value) is assigned to the alternative, using this approach, various criteria are given weight, $w$ that represent their partial contribution to the overall score, based on how important this criteria is for decision maker. Most commonly used is an additive value function (AVF).

i. MAVT (multi attribute value theory)

MAVT is a simple and user-friendly approach where the DMs in the cooperation with the analyst, only need to specify value functions and define weights for the criteria (Figueira et al., 2004).

ii. MAUT (multi attribute utility theory)

This is an extension to MAVT, more rigorous methodology for how to incorporate risk preferences and uncertainty into multicriteria decision support methods (Keeney \& Raiffa, 1976).

iii. AHP (analytical hierarchy process)

Similar to MAVT which use pair-wise comparisons- used both to compare the alternatives with respect to the various criteria and to estimate criteria weights (Saaty, 1980).

b. Goal, aspiration and reference level models. Examples of models;

i. Goal Programming

Is a try to determine the alternatives that in some sense are the closest to achieve a determined goal or aspiration level and often used as a first phase of a multicriteria process where there are many alternatives (Charnes et al., 1955).

ii. STEM (step method)

The ideal solution used as a goal for each criteria, the weights for the criteria are not specified by the decision maker, but are calculated by the relative range of values available on each criteria (Figueira et al., 2004).

c. Outranking models

The alternatives are compared pair-wise to check which of them is preferred regarding each criteria. When aggregating the preference information for all the relevant criteria, the model determines to what extent one of the alternatives can be said to outrank another. For example, alternative an outrank $b$ if there is enough evidence to conclude that $a$ is at least as good as $b$ when taking all criteria into account.

i. ELECTRE

Developed as an alternative to utility function and value function methods, the main idea is to choose alternative that are preferred for most of the criteria (Figueira et al., 2004).

ii. PROMETHEE

A pair-wise comparison of alternatives is performed to make up a preference function for each criterion (Brans and Vincke, 1985). 


\section{Motivation}

Current Web-based systems have limitations to assist DMs in decision-making especially in tendering processes. Those systems only serve as an interface between the clients and contractors. They receive tenders' information (input) from the clients and display tenders' information (output) for the contractors. After the tender documents are collected, clients will take that information and do the evaluation manually.

There are no exact tender evaluation system has been developed to assist DMs in decisionmaking as we planned to achieved in this research. As stated in previous section, we introduce iWDSS-Tender as a perfect solution with a wide range of abilities of intelligent systems, Web-based and DSS. iWDSS-Tender is going to be a big help for the DMs to assist them in decision-making process during the tender evaluation phase.

\section{Research approach}

The approach we use in this research is as per Figure 1. The development of iWDSS-Tender involves 4 main phases of approach. There are:

\section{a) Feasibility study}

The research starts with a complete study on the research problem of the current practices for tender evaluation process. We refer guidelines and standards of tender conventional work flow from JKRM to get better understanding of the process. In this phase we define iWDSS-Tender as the best solution and we do the further study on other underlying disciplines such as intelligence, Web-based and DSS. The best decision-making model and intelligent DSS model are then determined.

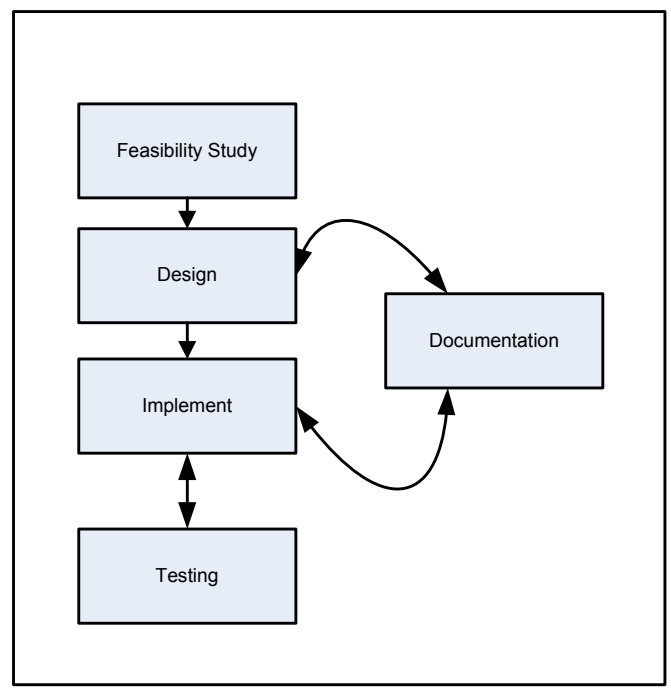

Fig. 1. iWDSS-Tender Research Approach

\section{b) Design}

In design phase, we design the framework which depicts the iWDSS-Tender as a whole. We also specified where to apply the intelligence element in the evaluation phase. User 
interface, requirements, specifications and constraints of the iWDSS-Tender are also emphasized during the design phase.

c) Implement

Implement phase is where all the designs previously created are implemented into real system by following the requirements, specifications and constraints defined. For example, implementation of the iWDSS-Tender database(s) and forms design.

d) Testing

We perform all modules, subsystems and system testing concurrent with the implementation. The testing must be done concurrently with the implementation therefore we can determine the errors at the early stages. For each iWDSS-Tender evaluation submodule, testing will be conducted once the sub-module program is ready.

e) Documentation

Documentations of iWDSS-Tender is prepared after each phases or actions taken, which means that the documentation phase is also must be done concurrently with other phases. Documentation phase is important as records of the iWDSS-Tender development.

\section{Phases of tender evaluation}

Figure 2 shows the conventional work flow of the tender evaluation process. The tender evaluation process takes place after the system list down all qualified tenders. The list of qualified tenders will be forwarded to the tender evaluation module for more detailed evaluation. Tender evaluation consists of two evaluation phases:

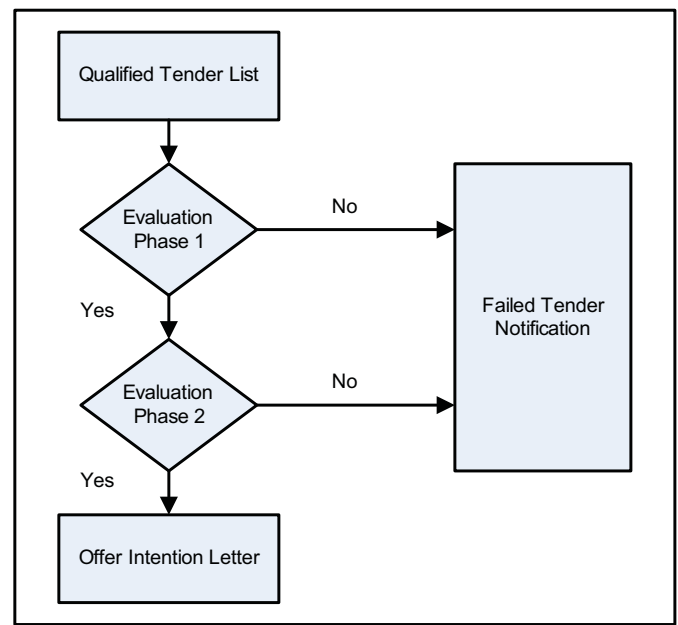

Fig. 2. Tender Evaluation Workflow

\section{a) First Evaluation Phase}

In first tender evaluation phase, all qualified tenders will be going through basic completeness document, financial and capital analysis. Tender documents that fail to fulfill all this basic analysis will then be discarded for second evaluation phase and system will send them a failure notification. The successful tenders will then be listed for the next evaluation phase. The first evaluation phase is as per Figure 3. 


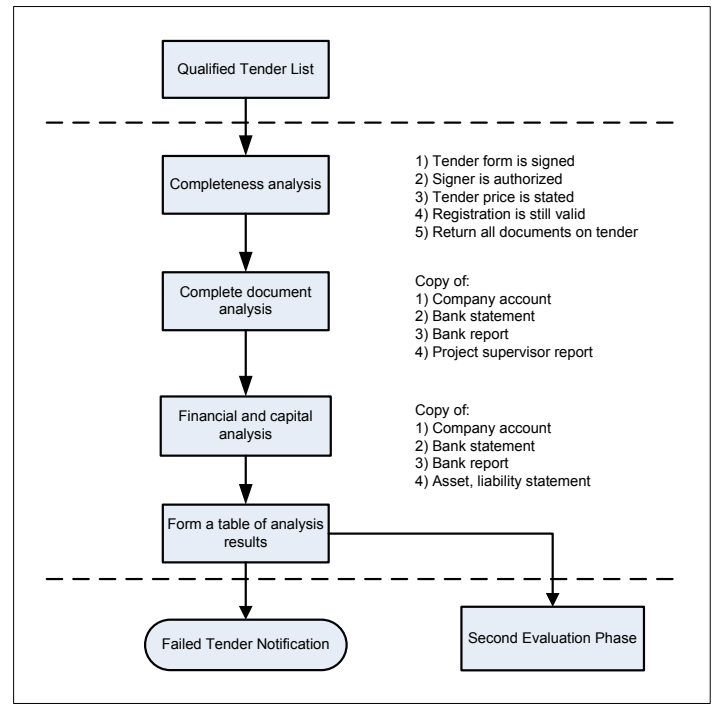

Fig. 3. First Evaluation Phase

\section{b) Second Evaluation Phase}

Figure 4 depicts the second evaluation phase. In this phase, tenders will be reexamined for calculating financial capability, experiences, technical staff and tools ownership. Each criterion will be given points for each item DMs scales. As an example for experience criterion, Tender A has three years of experiences and Tender B has 4 years of experiences. DMs decided that the years of experiences will be used as the scale for the item. Therefore, Tender A gets 3 points and Tender B gets 4 points. We expect a list of successful tenders with their overall points. The total points will be compared to the Minimum Evaluation Marks (MEM).

Those tenders that failed to reach the MEM are considered failed. Those success tenders are listed down based on the number of alternatives that the DMs want. The DMs will use this list to help them decide which tender to be selected. In the phase we will implement the intelligent model of MCDM analysis.

\section{Research framework}

The framework for this research is shown in Figure 5. iWDSS-Tender consists of 4 major modules; User Interface (UI), Database (DB), Knowledge-base (KB) and Model-base (MB).

i. User Interface

User interface acts as a medium between user and the iWDSS-Tender. In this research, there are 2 types of user (i.e. contractors and clients). Clients are the DMs. At the initial process, contractors provide iWDSS-Tender with tender information such as the tender details and contractor details.

ii. Database(s)

All tender information provided by users will be stored in the DB. This information might be retrieved by $\mathrm{KB}$ or $\mathrm{MB}$ to generate decision alternatives. Clients also might use DB for basic report analysis. 
iii. Knowledge-base

$\mathrm{KB}$ is necessary for understanding, formulating and solving problems. KB might contain facts of problem situation and theory of the problem area.

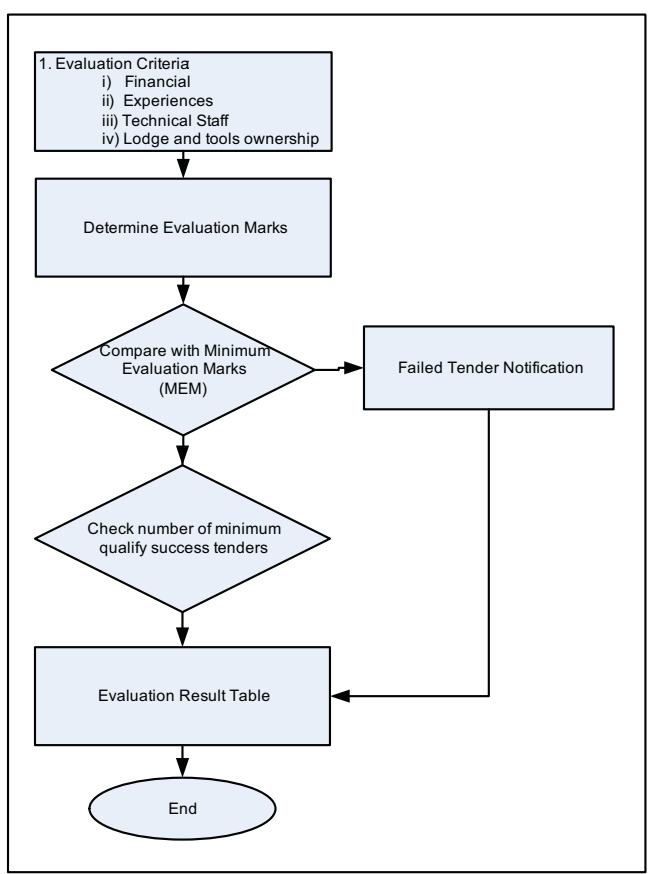

Fig. 4. Second Evaluation Phase

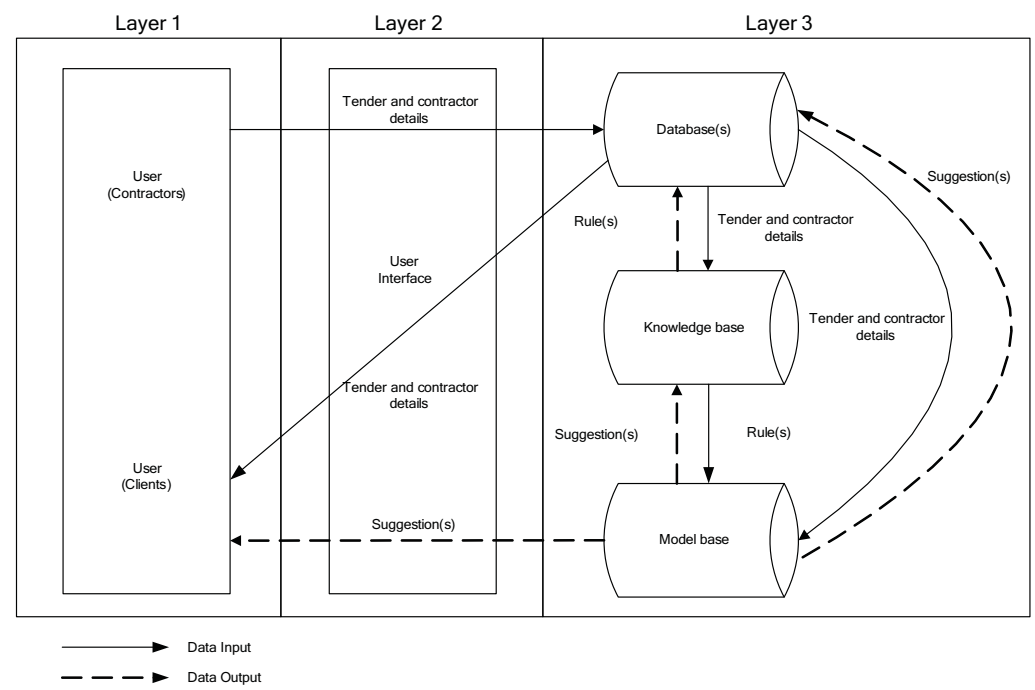

Fig. 5. iWDSS-Tender Detailed Framework 
iv. Model-base

Model used to perform multi criteria decision-making analysis resides in $\mathrm{MB}$, as well as the intelligent disciplines applied.

\section{Expected result}

iWDSS-Tender is expected to produce a complete electronic tendering systems. It helps users to do tender evaluation in a fast, efficient and accurate way. iWDSS-Tender provides a precise and transparent evaluation for DMs which may reduce the mistakes and increase the efficiency of the decisions.

\section{Conclusion}

Tendering is a crucial process, and it should implement a precise and transparent tender evaluation. This research introduces iWDSS-Tender as the best solution for tender evaluation. iWDSS-Tender allows DMs to take part in the decision-making process. At the final stage, DMs can select the best tender they prefer based on the points calculated by the MCDM analysis model. iWDSS-Tender also has the intelligent system capabilities such as learning ability, quickly and successfully response to new situations and applying knowledge to manipulate the environment. These capabilities give flexibility to the DMs and the decision-making process itself.

\section{References}

Brans, J. P. \& Vincke, P. (1985) A Preference Ranking Organization Method. Management Science, 31, 647-656.

Charnes, A., Cooper, W. \& Ferguson, R. (1955) Optimal Estimation Of Executive Compensation By Linear Programming. Management Science, 138-151.

Eom, S. B. (2001) Decision Support Systems, International Encyclopedia Of Business And Management, London, International Thomson Business Publishing Co.

Fakhreddine O. Karray, C. D. S. (2004) Soft Computing And Intelligent Systems Design Theory, Tools And Applications, Addison Wesley.

Figueira, J. E., Greco, S. \& Ehrgott, M. (2004) Multiple Criteria Decision Analysis: State Of The Art Surveys, New York, Springer.

Haykin, S. (1994) Neural Network: A Comprehensive Foundation, Macmillan.

Keeney, R. \& Raiffa, H. (1976) Decisions With Multiple Objectives: Preferences And Value Tradeoffs, Wiley.

Mccarthy, J. (2004) What Is Artificial Intelligence?

"MSC e-Government Flagship Applications," vol. 2007. [Online]. Available: http:/ / www.eperolehan.com.my

Saaty, T. L. (1980) The Analytic Hierarchy Process, Mcgraw Hill.

Sprague R. H. Jr., C. E. D. (1982) Building Effective Decision Support System, Prentice Hall.

"Tender Direct". [Online]. Available: http://www. tenderdirect.com.my

"Tendersystem". [Online]. Available: http://www. tenderdirect.com.my

Turban, E., Aronson, J. E. \& Liang, T. P. (2005) Decision Support Systems And Intelligent Systems, United States Of America, Pearson Education Ltd. 


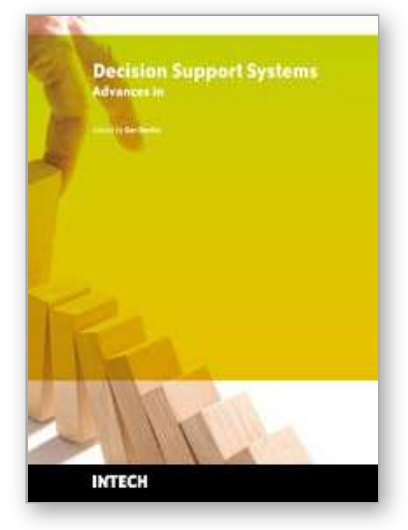

\author{
Decision Support Systems Advances in \\ Edited by Ger Devlin
}

ISBN 978-953-307-069-8

Hard cover, 342 pages

Publisher InTech

Published online 01, March, 2010

Published in print edition March, 2010

This book by In-Tech publishing helps the reader understand the power of informed decision making by covering a broad range of DSS (Decision Support Systems) applications in the fields of medical, environmental, transport and business. The expertise of the chapter writers spans an equally extensive spectrum of researchers from around the globe including universities in Canada, Mexico, Brazil and the United States, to institutes and universities in Italy, Germany, Poland, France, United Kingdom, Romania, Turkey and Ireland to as far east as Malaysia and Singapore and as far north as Finland. Decision Support Systems are not a new technology but they have evolved and developed with the ever demanding necessity to analyse a large number of options for decision makers (DM) for specific situations, where there is an increasing level of uncertainty about the problem at hand and where there is a high impact relative to the correct decisions to be made. DSS's offer decision makers a more stable solution to solving the semi-structured and unstructured problem. This is exactly what the reader will see in this book.

\title{
How to reference
}

In order to correctly reference this scholarly work, feel free to copy and paste the following:

Noor Maizura Mohamad Noor and Mustafa Man (2010). iWDSS-Tender: Intelligent Web-based Decision Support System for Tender Evaluation, Decision Support Systems Advances in, Ger Devlin (Ed.), ISBN: 978953-307-069-8, InTech, Available from: http://www.intechopen.com/books/decision-support-systemsadvances-in/iwdss-tender-intelligent-web-based-decision-support-system-for-tender-evaluation

\section{INTECH}

open science | open minds

\section{InTech Europe}

University Campus STeP Ri

Slavka Krautzeka 83/A

51000 Rijeka, Croatia

Phone: +385 (51) 770447

Fax: +385 (51) 686166

www.intechopen.com

\section{InTech China}

Unit 405, Office Block, Hotel Equatorial Shanghai

No.65, Yan An Road (West), Shanghai, 200040, China

中国上海市延安西路65号上海国际贵都大饭店办公楼 405 单元

Phone: +86-21-62489820

Fax: $+86-21-62489821$ 
(C) 2010 The Author(s). Licensee IntechOpen. This chapter is distributed under the terms of the Creative Commons Attribution-NonCommercialShareAlike-3.0 License, which permits use, distribution and reproduction for non-commercial purposes, provided the original is properly cited and derivative works building on this content are distributed under the same license. 